\title{
Medical and Medication Errors: A Partial Summary of Reports by the Institute of Medicine and the Quality Interagency Coordination Task Force
}

OBJECTIVE: To summarize information on medical errors as reported by the Institute of Medicine (IOM) in To Err is Human: Building a Safer Health System and the Report of the Quality Interagency Coordination Task Force (QulC) in a manner that will clarify medical and medication error problems and suggest opportunities for change.

The Agency for Healthcare Research and Quality (AHRQ), Office of Health Care Information has disseminated information on the problem of medical errors and has asked that AHRQ research be used in educational offerings. The information and examples in this continuing education article were extracted and summarized from the report of the Institute of Medicine (IOM), To Err is Human: Building a Safer Health System and the report to the president by the QulC, "Doing What Counts for Patient Safety." Information on of these and other AHRQ publications may be obtained from www.ahrq.gov or by telephone at 1-800-358-9295.

KEYWORDS: Medical error, medication error

J Managed Care Pharm 2001: 62-68

\section{Aulho}

LNDA NORTON Pharm D. is Associate Professor of Pharmacy

Practice University of the Padfic, School of Pharmagy and Healith Science Stockton, CA.

4iv AUTHOR GORRESPONDENCE Ginda I. Norton, Pharm D., Associate Professor of Pharmacy practice Unversity of the Pacific School of Pharmad and Health Sciences, 3601 Pacific Avenue, Stockton, CA 95211 Tel 209-946-2412,Fax,209-946-3180, E-mail lnorton@uop.du

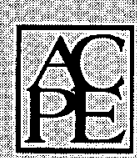
The Academy of Managed Care Pharmacy is approved by the American Coundi on Pharmaceutical Education as a provider of continumg pharmaceutical education Indinduals may obtan up to 1 contact hotur of credit or 010 Continuing Education Unit (CEU). The ACPE number is 233-00000-000 104 Certificates will be mailed within eight weeks to participants who successfully complete the EE exam and achieve a score of $70 \%$ or more and submit the exam to AMCP prior to February 28, 2002. Learning bbjectives and test questions follow on page 69 1.1. Copyrghto 2001 A cademy of Managed Care Pharmas, Ind All rights. reserved:
$\mathrm{T}$ by Linda L. Norton that, "It is clear that, although the United States provides some of the best health care in the world, the numbers of errors in health care are at unacceptably high levels." As detailed in the summary, estimates from 1991 and 1999 are that adverse events, which include medical errors, occur in $3-4 \%$ of patients. A 1994 study suggested that errors occurred in patient care in an intensive-care unit (ICU) at the rate of almost two errors per patient per day, which means that patients in that ICU got the correct care about $99 \%$ of the time. To put these rates in perspective, an error-free rate of $99.9 \%$ (which is a rate 10 times better than the suggested rate for health care in the ICU setting) would translate in the banking industry to an hourly rate of 32,000 checks deducted from the wrong account. In aviation, this rate would result in two dangerous landings at O'Hare International Airport each day.

The IOM estimates that the costs of medical errors in the United States including lost income, disability, and health care may be $\$ 17-\$ 37.6$ billion or more annually. ${ }^{2,3}$ In contrast, Johnson and Bootman in 1995 estimated the cost of drug-related morbidity and mortality in ambulatory-care patients to be $\$ 30.1-\$ 136.8$ billion. ${ }^{4}$ These costs are from a variety of drugrelated problems including patient compliance issues and medical/medication errors.

Whatever the cost of medical and medication errors, the situation is made worse by the fact that many errors are preventable. The IOM estimates that more than half of the adverse medical events occurring each year are attributable to preventable medical errors. These errors result in the deaths of tens of thousands of patients. Many of the preventable medical errors that occur involve medications. IOM has estimated that over 7,000 of the preventable deaths that occur each year are attributable to medication errors. This number is greater than the number of injuries that occur in the workplace each year., 5 Unfortunately, medical mistakes result in more severe consequences than errors in most other industries. Serious medical errors cause death and disability rather than inconvenience (see Table 1, page 63)

Amazingly, the problem of medical errors is old news. A 1964 report indicated that the U.S. health care system had a 


\section{Medical and Medication Errors: A Partial Summary of Reports by the Institute of Medicine and the Quality Interagency Coordination Task Force}

\section{TABLE 1 Definitions and Glossary of Terms in the IOM and QuIC Reports}

IOM definition of error: The failure of a planned action to be completed as intended or the use of a wrong plan to achieve an aim.

QuIC definition of error: The failure of a planned action to be completed as intended or the use of a wrong plan to achieve an aim. Errors can include problems in practice, products, procedures, and systems.

Adverse event: An injury that was caused by medical management and that results in measurable disability.

Unpreventable adverse event: An adverse event resulting from a complication that cannot be prevented given the current state of knowledge.

Medical error: An adverse event or near-miss that is preventable given the current state of medical knowledge

Near miss: An event or situation that could have resulted in an accident, injury, or illness, but did not, either by chance or through timely intervention.

System: A regularly interacting or interdependent group of items forming a unified whole.

Systems error: An error that is not the result of an individual's actions but the predictable outcome of a series of actions and factors that comprise a diagnostic or treatment process.

Patient safety: Applies to initiatives designed to prevent adverse outcomes from medical errors. The enhancement of patient safety. encompasses three complimentary activities: preventing errors, making errors visible, and mitigating effects of the errors.

Sources: Doing what counts for patient safety: Federal actions to reduce medical errors and their impact, Report of the Quality Interagency Coordination Task Force (QuIC) to the President, February 2000; available online at www.quic.gov/report/toc.htm. Committee on Quality of Health Care in America, Institute of Medicine. To err is human. Building a safer health system. Kohn LT, Corrigan JM, Donaldson MS, eds. Washington: National Academy Press, 1999.

serious problem. ${ }^{1.6}$ But the $10 \mathrm{M}$ report has made news: information from the report has appeared on the evening news and in major news magazines. Consumers and purchasers of health care have read. recent estimates that preventable medication errors probably increase hospital costs by approximately $\$ 2$ billion annually, ${ }^{1}$ and they have heard some of the frightening information from the IOM. For example, current IOM estimates are that 44,000-98,000 Americans die each year as a result of an adverse event related to medical care that was supposed to prevent, diagnose, treat, or cure disease or improve quality of life, ${ }^{2,7}$ This makes death from medical error the eighth-leading cause of death in the United States, killing more Americans than motor vehicle accidents, breast cancer, or acquired immunodeficiency syndrome (AIDS).

Focusing on complications of medication use and medication error, health care consumers have learned that even in 1977 reports indicated that $50 \%$ of all prescriptions are used incorrectly. ${ }^{1.8}$ Again, as reported in the QuIC and IOM reports, in 1995, according to Bates, problems with medications still accounted for about $10 \%$ of all hospital admissions. ${ }^{9}$ Health care consumers and purchasers have learned from a 1991 Harvard practice study of adverse medical events that $19 \%$ of all adverse events involved complications of medication use, and $58 \%$ of drug complications that caused injury or death were preventable. ${ }^{10}$ In addition, they now know that of the adverse events involving medication use, $45 \%$ were due directly to medication errors (i.e., mistakes in writing, dispensing, or administering medications) and were potentially preventable. ${ }^{10}$

Problems are evident in the ambulatory-care setting, too. A study of 1,000 ambulatory-care patients found medication side effects in 42 patients; 23 patients $54 \%$ of those with side effects) had preventable side effects.

Consumers and health care purchasers and providers agree that the system needs improvement and patients need to be protected from preventable medical errors. The questions that need to be answered at the national, state, health care system, and provider levels are "What can be done to protect patients," and "What is being done right now?" These are the questions that the $10 \mathrm{M}$ and QuIC reports seek to answer.

\section{I0M and QulC Recommendations}

The $10 \mathrm{M}$ has recommended that the United States establish a national goal to reduce the number of medical errors by $50 \%$ over five years. To reach that goal, the IOM suggests a multitiered approach that would establish a national focus on patient safety, allow us to identify and learn from medical errors, raise standards and expectations for medical safety, and improve the safety of medical practices at the delivery level.

The Clinton administration has supported the IOM recommendations and has included $\$ 20$ million in the fiscal year 2001 budget to support a Center for Quality Improvement and Patient Safety at the Agency for Healthcare Research and Quality (AHRQ). Establishing a national focus on patient safety and creating leadership, research, tools, and protocols that enhance our knowledge of patient safety could be primary goals for the center. The center may also be expected to track progress toward goals and develop a research agenda and disseminate grants. The center may further evaluate methods for identifying and preventing errors, and communicate activities that improve patient safety 


\section{Medical and Medication Errors:}

\section{A Partial Summary of Reports by the Institute of Medicine and the Quality Interagency Coordination Task Force}

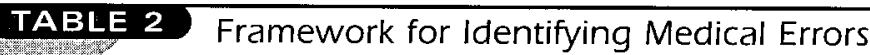

Patient Receives Treatment

\begin{tabular}{|c|c|c|c|c|c|}
\hline \multicolumn{2}{|c|}{ No Error } & \multicolumn{4}{|c|}{ Error } \\
\hline \multirow[t]{3}{*}{ Good outcome } & \multirow{3}{*}{$\begin{array}{l}\text { Bad outcome } \\
\text { Unpreventable } \\
\text { adverse event }\end{array}$} & \multicolumn{2}{|c|}{ Minor } & \multicolumn{2}{|c|}{ Serious } \\
\hline & & Caught & Not caught & Caught & Not Caught \\
\hline & & Near miss & $\begin{array}{c}\text { Minor or no injury } \\
\text { Preventable } \\
\text { adverse event }\end{array}$ & Near miss & $\begin{array}{l}\text { Patient injury } \\
\text { Preventable } \\
\text { adverse event }\end{array}$ \\
\hline
\end{tabular}

Source: Doing what counts for patient safety: Federal actions to reduce medical errors and their impact, Report of the Quality Interagency Coordination Task Force (QuIC) to the President, February 2000; available online at www.quic.gov/report/toc.htm.

Identifying and learning from medical errors has been a goal of many pharmacy and therapeutics (P\&T) committees and continuous quality improvement initiatives. However, the IOM has called for a nationwide effort that includes a reporting system with both mandatory and voluntary components. In the suggested reporting system, state governments would collect standardized information on medical errors that result in death or serious harm. This plan would start with hospitals and would eventually require reports from other institutional and ambulatory-care systems. If state governments fail to implement a mandatory system, then, according to the IOM and QuIC reports, the Department of Health and Human Services should develop the system.

The IOM also recommended a variety of options for morelimited voluntary reporting systems in all 50 states. Importantly, the IOM also recommended that Congress extend peer review protections to data related to patient safety and quality improvement collected through the reporting systems. One example of a mandatory reporting system that works is the one already in place at many Veterans Affairs (VA) facilities. The system collects information on adverse events, medication errors, close calls, and other patient-safety-related factors.

Raising the standards and expectations for improvements in patient safety and implementing safe practice at the delivery level will require support from health care purchasers, oversight and accrediting agencies and organizations, and members of the medical professions. The IOM has recommended including patient safety in performance standards and expectations for health care organizations and has suggested that health care organizations implement "meaningful patient safety programs with defined executive responsibility." They also suggest that purchasers of health care, both public and private, provide incentives to organizations that show evidence of ongoing improvements in patient safety. The IOM has further recommended that health care organizations implement proven med- ication safety practices such as automated order entry, barcoding for blood transfusions and medications, integrated pharmacy system profiles, drug-utilization review, and patient counseling.

Interestingly, the IOM's recommendations do not stop at the heath care system level. They indicate that physicians, nurses, and other key health care providers should be required to meet performance standards and expectations that focus greater attention on patient safety. Included in this concept is a call for periodic reexamination and relicensing based on competence and knowledge of safety practices. The IOM also recommends that professional societies show a commitment to patient safety by establishing permanent committees dedicated to safety improvement.

From the federal perspective, QuIC has proposed that all hospitals participating in the Medicare program implement patient safety programs. The Health Care Financing Administration (HCFA) will also be publishing regulations in 2000/2001 that require hospitals participating in the Medicare program to have ongoing medical-error-reduction programs including mechanisms to reduce medication errors. There are several possible options for these programs, including automated pharmacy order entry and automatic safeguards against harmful drug reactions and other adverse events.

QuIC is also proposing that the approximately 300 plans in the Federal Employee Health Benefits Program implement patient-safety programs (beginning in 2001) and that privatesector employers and employees incorporate patient safety into purchasing decisions. This year the Department of Labor will include information on medical errors in the Health Benefits Education Campaign that will educate employees about issues of quality and safety. under employer-provided health benefits.

Improved patient-safety programs are already in progress at VA and Department of Defense (DOD) facilities. At the VA, money to increase the requirements for provider patient-safety training from 15 to 20 hours per year has been budgeted. DOD 


\section{Medical and Medication Errors: A Partial Summary of Reports by the Institute of Medicine and the Quality Interagency Coordination Task Force}

\section{TABLE 3 Important Characteristics of Error-reducing Industries}

- Intolerance of high error rates-ambitious targets for error reduction

- Tracking mechanisms that expose errors

- Abundant reports of errors and near misses

- Error investigation that include root-cause analysis

- An error-reduction systems approach that encompasses most or all factors-both human and technical-and seeks organizational solutions

- A focus on systems solutions, not assigning blame to individuals

- Developing an organizational culture that enhances safety and error reduction

- Allotment of adequate resources for error-prevention initiatives and support systems

- Recognition of novel solutions and the ability to combine disciplines (psychology and engineering) to create unique solutions

Source: Doing what counts for patient safety: Federal actions to reduce medical errors and their impact, Report of the Quality Interagency Coordination Task Force (QuIC) to the President, February 2000; available online at www.quic.gov/report/toc.htm.

\section{TABLE 4. Obstacles to Error-Reducing Quality- Why Improvement Programs in Health Care Wyt Organizations}

- Lack of awareness of the problem

- Lack of protection from legal discovery and liability, which results in concealment

- Primitive medical information systems, which impede data collection and analysis

- Inadequate allocation of resources for quality improvement and error prevention, especially in systems with fragmented budgeting and reporting

- Inadequate knowledge of the frequency, cause, and impact of errors, and of effective methods for error prevention

- Lack of understanding of systems-based approaches to error reduction, such as those in aviation, and the perceived, difficulty of adapting those approaches to health care

- Failure to apply a consistent strategy

Source: Doing what counts for patient safety: Federal actions to reduce medical errors and theirimpact, Report of the Quality Interagency Coordination Task Force (QuIC) to the President, February 2000; available online at www.quic.gov/report/toc.htm.

facilities are getting a new computerized medical record that will support an automated-entry order system for pharmaceuticals that will keep all relevant clinical information available.
These systems will be phased in over three years.

The IOM further emphasized that medication errors should not be studied apart from other health care issues. Overall, the problem of medical and medication errors should be viewed as part of the broader problem of health care quality. Three major quality problems were identified in the IOM report:

- Problem: Overuse of the health care system.

Result: Little or no net benefit to patients.

- Problem: Underuse of the health care system.

Result: Potentially beneficial service not received.

- Problem: Misuse of the system.

Result: Service inappropriately used.

Medical errors are, for the most part, misuse, but may also be categorized as overuse or underuse. This is particularly true when overuse (i.e., unnecessary service) leads to patient harm, or when an error leads to underuse, such as a patient not recieving a needed treatment.

\section{A Framework for Identifying Medical Errors}

As demonstrated in Table 2, page 64, each time a patient receives treatment, that treatment may be completed without error or an error may occur. If the treatment is completed without error, the patient may have a good medical outcome or may still have a poor medical outcome because of an underlying condition or disease. If an error occurs, that error may be minor or serious; each may be caught and avoided or not, resulting either in a close call or in patient injury.

The IOM and QuIC reports emphasize that there are problems associated with the lack of a universally accepted taxonomy for medical errors. They have pointed to reporting systems and taxonomies such as those developed by National Coordinating Council for Medication Error Reporting and Prevent (NCCMERP) and the Joint Commission on Accreditation of Healthcare Organizations (JCAHO) as well as systems that classify errors using legal definitions (e.g., negligence), type of setting (e.g., ambulatory clinic), or individual involved (e.g., pharmacist, nurse, patient). NCCMERP classifies errors by the type of service provided. " JCAHO classifies errors based on the severity of the resulting injury.

There is agreement that there is no ideal classification that fits all needs, and that the classifications of errors must meet the needs of the program to which it is applied. A reporting and classification system must have the ability to allow effectual reporting and analysis of errors and improve the health care facility's ability to measure and increase patient safety. And, indeed, classification may not be necessary if the information collected is adequate for the purpose. The QuIC report uses the narrative reporting style of the Aviation Safety Reporting System as an example of an effective system that can be successfully used for error reporting without the need for a classification system.

A number of industries other than health care have institut- 


\section{A Partial Summary of Reports by the Institute of Medicine and the Quality Interagency Coordination Task Force}

ed quality and safety-improvement systems as. well as errorreduction systems. The health care industry, however, has been reported to be at least 10 years behind other industries in using quality and safety improvement systems. A review of industries that have been successful in improving quality and reducing errors has shown that there are many similarities in their errorreducing cultures (See Table 3, page 65.).

While there is no perfect solution for all settings, the considerations and characteristics listed in Table 3 contribute to a general approach, which if consistently applied can lead to good results.

\section{Barriers to Identifying and Reducing Medical Errors}

While health care shares many opportunities for improvement with non-health care industries, health care is unique in several ways. One of the most important differences is that the current error rate in health care is much higher than the error rate in almost any other industry. Even if the medical error rate were improved to only 1 incident in 1,000, that level of error would still not be tolerable in areas such as aviation or banking. Which leaves the question, "Why is health care different?" To date, the answer is unknown. One obvious answer is that in health care, even a simple procedure requires many steps and many interactions between humans and technology, and every step and every interaction is an opportunity point for a successful errorfree procedure or a problem-prone, error-filled procedure. As reported in the QuIC report, one observer has suggested that medical errors occur because the knowledge base necessary to effectively and safely deliver health care exceeds the capacity of the human brain

Fragmentation in health care is a contributor to the error problem and will be a complicating factor in any solution. The prescription medication process is one example of fragmentation. In most settings, before obtaining prescription medication the patient must be seen by a physician or another prescriber. The prescriber then orders the medication. The prescription is transmitted to the pharmacy. It may be carried by the patient or faxed or called to the pharmacy by the prescriber or the prescriber's designee for transcription into the pharmacy's processing computer. In a few rare cases, the prescriber may transmit the order directly to the processing computer. Then the prescription can be dispensed. In many cases, it will be filled by a pharmacy technician and checked by a pharmacist. The prescription must still be delivered to the patient and finally be administered to the patient. There are thus five major steps in the processing of one prescription: ordering, transcribing, dispensing, delivering, and administering. There may be as many as eight or more individuals involved in the process of getting the medication administered. Clearly this is a complex system-a system prone to human and technologic failures.

Organizational fragmentation and inadequate communica- tion among departments and divisions contributes to increased difficulty in initiating a systemwide error-reduction program. Innovation and programs that are working well in one area may not spread to another area or may be only grudgingly accepted, since each area perceives its needs to be unique. Even in settings where good programs to reduce systems error exist, it may be difficult to determine which outcomes should be attributed to excellent care and which to poor care. The variability in patient response is almost unfathomable. A poor outcome in one patient may occur despite excellent, error-free care while a good outcome in another patient may occur despite a number of medical errors. The complexity of individual patients' response cannot be adequately detailed in most error identification and reduction systems.

The traditional approach to error reduction (i.e., finding the guilty party and punishing), rather than the use of a systems approach, is a serious problem and is counterproductive. It may cause errors to be hidden rather than examined. Hiding problems contributes to the ongoing error problem, since many if not most errors can be attributed to systems problems and corrected if they are identified. Overwork and long hours are problematic within many health care systems. These conditions represent a system problem that can contribute to fatigue and the ensuing medical errors. However, even in the best systems, humans make mistakes, technology fails, and errors occur. In the best of cases, the system will allow the error to be detected and the resulting problems minimized. In the worst cases, a patient will be seriously injured or die.

Other obstacles to error-reducing quality-improvement programs within health care organizations are summarized in Table 4 , page 65 . These barriers are greater in non-medical-center settings, such as those for community care and ambulatory patients, than in a health care center. This is due, at least in part, to the lack of an organized system and trained personnel.

\section{Developing an Effective Error-Reduction System}

As detailed in the QuIC report, effective error-prevention systems should be developed as locally directed programs with complementary support and guidance from federal, state, and nongovernment organizations. A comprehensive approach will require specifically designated personnel to identify and monitor the occurrence of errors especially in patients at highest risk, determine the root of preventable errors, and analyze, interpret, and disseminate data to stakeholders. Additionally, designated personnel will be needed to implement error reduction strategies, work with experts (e.g., clinical, epidemiologic, and management) when technical support and on-site investigations are required, and evaluate the impact of the programs that are implemented

Error-surveillance systems can be active (i.e., soliciting case reports directly from potential reporting sources) or passive (i.e., practitioners report incidence). Active systems provide more 


\section{Medical and Medication Errors: \\ A Partial Summary of Reports by the Institute of Medicine and the Quality Interagency Coordination Task Force}

complete and accurate information, but are expensive to start and maintain. The QuIC report concludes systems designed for quality improvement through error reduction can work if those who report are assured of confidentiality, and protection from legal liability, are given timely feedback on data from the system and are not unduly burdened by the reporting system.

\section{What Role Will the Food and Drug Administration Play in Reducing Medication Errors?}

As quoted from the QuIC report, within the 2000/2001 year the Food and Drug Administration (FDA) is initiating programs to:

- Develop additional standards for proprietary drug names to avoid name confusion.

- Develop standards for packaging to prevent dosing and drug mix-ups.

- Develop new label standards for drugs, highlight drug-drug interactions and potential dosing errors, and address other common errors related to medications.

- Implement the Phase II pilot study of the congressionally mandated Medical Product Surveillance Network (MedSuN).

- Intensify efforts to ensure manufacturers' compliance with FDA programs, specifically naming, labeling, and packaging.

- Provide access to databases linked to health care systems and other sources of adverse events and marketing data, and link these to existing registries of product users.

- Complete the online Adverse Event Reporting System (AERS) for drugs and biologics.

- Strengthen FDA analytical and investigative capacities.

- Strengthen FDA outreach activities and collaboration with other government agencies and stakeholders."

\section{Opportunities for Consumer Awareness of Medical and Medication Errors}

Over the next few years, federal agencies will develop and coordinate information campaigns for their constituents and beneficiaries that focus on the problems of medical and medication errors. In addition, the AHRQ will develop generic material for the public on how consumers can help in preventing medical errors, and how they can obtain information on health care safety in their communities.

The FDA will, within one year, increase collaborative programs with patient and consumer groups. Within that year, they will also increase interactions with the public through consumer and patient organizations and grass-roots informational meetings. The meetings will focus on patient needs and safe use of medical products, especially those for home use. Consumers will also be asked about how to reach more people on safe use of medications.

\section{Learning from Errors: The Unanswered Questions}

There is much to be done to decrease medical and medication errors. Many questions remain, including:
- Is there a set of "egregious errors" that are preventable and should never occur?

- Would patients benefit from knowing the error rates for various health care plans, delivery systems, and providers?

- What are the options for mandatory reporting systems and how should the information be used to reduce errors? Will this information help with evidenced-based, systems-level changes?

- How will health care plans develop error-reduction programs? Should this information be reported on Web sites open to the public?

- What patient-safety practices can institutions undertake? Should this information be reported?

- Should the FDA report to the public on the safety of drugs, devices, and biologic products? Will this reporting make a difference?

- Are state and federal reporting and private accrediting or oversight bodies helpfül in assuring public accountability for safety?

- Should the Office of Personnel Management (OPM) require health plans to describe their patient-safety initiatives?

- Is there value to punitive reporting systems?

- Are some products, procedures, services, and systems more error-prone than others? Should we focus more resources on these areas?

- What additional skills are needed to analyze adverse events and near misses (e.g., root-cause analysis, trending, search tools)?

- What role, at what level, and in what arena do continuing education, quality forums, discussions, safety centers, and others play?

- What measures will encourage error reporting?

- What roles do simulation and automation play?

- Is there a need for standardized platforms for automated physician order entry, electronic patient records, and a common clinical lexicon for practitioners?

- How do initiatives to improve safety fit into the pharmacy managers' program under an expanded Medicare drug benefit? Many opportunities exist for health care systems, health care purchasers, and health care providers to improve patient safety and reduce errors. ${ }^{12-15}$ However, one of the keys to reducing errors may be consumer involvement. Consumers who are involved in their own health care, ask questions, and make informed decisions rather than act as passive recipients of care can serve as a final check on the health care system. Informed patients may be more likely to accept recommended treatment and to do what they as a patient need to do to make their medical care work. The AHRQ has published a fact sheet for patients titled, "20 Tips to Help Prevent Medical Errors: Patient Fact Sheet," and there are a growing number of programs to make consumers more aware of the importance of becoming a 


\section{Medical and Medication Errors:}

\section{A Partial Summary of Reports by the Institute of Medicine and the Quality Interagency Coordination Task Force}

member of their own health care team..$^{16}$ The AHRQ patient fact sheet, programs for increasing consumer awareness of medical issues and problems, and other steps to reduce medical errors will be the focus of our next JMCP continuing education program.

\section{References}

1. Doing what counts for patient safety: Federal actions to reduce medical errors and their impact, Report of the Quality Interagency Coordination Task Force (QuIC) to the Ptesident, February 2000; available online at www.quic.gov/report/toc.htm.

2. Committee on Quality of Health Care in America, Institute of Medicine. To err is human. Building a safer health system. Kohn LT, Corrigan JM, Donaldson MS, eds. Washington: National Academy Press, 1999.

3. Agency for Healthcare Research and Quality. Medical errors: The scope of the problem. Fact sheet, Publication No. AHRQ 00-P037. Rockville, MD: AHRQ, February 2000; available online at www.ahrq.gov/qual/errback.htm.

4. Johnson JA, Bootman JL. Drug-related morbidity and mortality. A cost-ofillness model. Arch Intern Med 1995; 155: 1949-56.

5. National Academies Office of News and Public Information. Preventing death and injury from medical errors requires dramatic, system-wide changes. Washington, DC: National Academies, November 1999; available online at www4 nationalacademies.org/news.nsf/isbn/0309068371? OpenDocument.

6. Schimmel EM. The hazards of hospitalization. Ann Intern Med 1964; 60: $100-10$.

7. Agency for Healthcare Research and Quality. Statement on medical errors. John M. Eisenberg, M.D., Director, Agency for Healthcare Research and Quality, before the Senate Appropriations Subcommittee on Labor, Health and Human Services, and Education, December 13, 1999, Washington. Rockville, MD: AHQR, 1999; available online at www.ahrq.gov/news/stat1213.htm.
8. Porter J, Jick H. Drug-related deaths among medical inpatients. JAMA 1977; 237: 879-81.

9. Bates DW et al. Incidence of adverse drug events and potential adverse drug events: Implications for prevention. ADE Prevention Study Group. JAMA $1995 ; 274: 29-34$.

10. Leape LL et al. The nature of adverse events in hospitalized patients. Results of the Harvard Medical Practice Study II: New Engl J Med 1991; 324 : $377-84$.

11. National Coordinating Council for Medication Error Reporting and Prevention. NCCMERP taxonomy of medication errors. Rockville, MD: USP, 1998; available online at www.nccmerp.org/aboutmederrors.htm.

12. Understanding and preventing drug misadventures. A multidisciplinary conference sponsored by the ASHP Research and Education Foundation in cooperation with the American Medical Association, the American Nursing Association, and the American Society of Hospital Phamacists. Am J Health Syst Pharm. 1995; 52; 369-416.

13. Re-engineering the medication use system: An interdisciplinary conference. Am J Health Syst Pharm. 2000; 57: 537-601.

14. National Coordinating Council for Medication Error Reporting and Prevention. Recommendations to reduce errors related to administration of drugs. Rockville, MD: USP, June 1999; available online at www.nccmerp.org/rec_990629.htm.

15. Agency for Healthcare Research and Quality. Reducing errors in health care. Translating research into practice. AHRQ Publication No. 00-PO58. Rockville, MD: AHRQ, April 2000; available online at www.ahrq.gov/research/errors.htm.

16. Agency for Healthcare Research and Quality 20 tips to help prevent medical errors. Patient Fact Sheet. AHRQ Publication No. 00-PO38. Rockville, MD: AHRQ, February 2000; available online at www.ahrq.gov/consumer/20tips.htm. 